\title{
The Development of Technology and Engineering Literacy Through STEM-Based Education
}

\author{
H. Firman, N. Y. Rustaman \\ Department of Science Education \\ Post Graduate Studies, Universitas Pendidikan Indonesia \\ Bandung, Indonesia \\ harry_firman@upi.edu, nuryanirustaman@upi.edu
}

\author{
I. R. Suwarma \\ Department of Physics Education \\ Post Graduate Studies, Universitas Pendidikan Indonesia \\ Bandung, Indonesia \\ rahmai@ymail.com
}

\begin{abstract}
Technology and engineering have become critical components of 21st-century life. Therefore, technology and engineering literacy (TEL) need to be achieved by youngsters, not only vocational and technological school students but also students at general secondary schools. As a result, general education at primary and secondary education should have a mission to develop students' TEL. However, so far there is no technology or engineering courses at primary and general secondary school level curriculum, so that formally no vehicle available to deliver technology and engineering knowledge and skills to support the development of TEL. In such circumstances science courses that exist in primary and general secondary school curriculum need to take a role to develop TEL in addition to its main function to develop students' scientific literacy. Therefore, this paper reviewed the study of technology and engineering literacy improvement in primary and secondary schools by investigating the implementation of methods in other countries. Japan and U.S was chosen as an investigated sample because of its development in STEM-based activity that was considered as an approach to deliver technology and engineering. The result showed that there were two methods implementation in formal and non-formal setting (out of school), that embedded engineering practice in the program activities.
\end{abstract}

Keywords-Technology and Engineering Literacy (TEL), STEMbased activity

\section{INTRODUCTION}

Technology is defined broadly as any modification of the natural world done to fulfill human needs or wants, and engineering is a systematic and often iterative approach to designing objects, processes, and systems to meet human needs and wants [1]. Technology includes not only its tangible products, but also knowledge and process necessary to create and operate those products. The infrastructure used for the design, manufacture, operation, and repair of technological products is also considered as part of technology. Most of modern technology is a product of science and engineering, and technological tools are used in both fields. While engineering is defined as both body of knowledge about the design and creation of human-made products and a process for solving problems under constraints including time, money, available materials, environmental regulations, manufacturability, etc [2]. Engineering utilizes concepts in science and mathematics as well as technological tools.

Technology and engineering are different but closely interrelated each other. The distinction between technology and engineering is that engineering can be viewed as a process of creating or designing, where as technology on the other hand can be viewed as the product of the process. Engineering activities results in a transformation of materials, energy, or information, whereas technology can be seen as things result from engineering.

The National Assessment and Educational Progress (NAEP) defines technology and engineering literacy (TEL) as the capacity to use, understand, and evaluate technology as well as to understand technological principles and strategies needed to develop solutions and achieve goals [3]. In technology and engineering literacy, students are expected to be able to apply particular ways of thinking and reasoning when approaching a problem. The NAEP specifies three interconnected areas of technology and engineering literacy:

- Technology and Society involves the effects that technology has on society and on the natural world and the ethical questions that arise from those effects.

- Design and Systems covers the nature of technology, the engineering design process by which technologies are developed, and basic principles of dealing with everyday technologies, including maintenance and troubleshooting.

- Information and Communication Technology includes computers and software learning tools, networking systems and protocols, hand-held digital devices, and other technologies for accessing, creating, and communicating information and for facilitating creative expression.

In all three areas of technology and engineering literacy, students are expected to be able to apply particular ways of thinking and reasoning when approaching a problem. These types of thinking and reasoning are referred to as "practices." The framework specifies three kinds of practices students are expected to demonstrate as shown in Table 1. 
TABLE 1. The NAEP Technology and Engineering Literacy Practice [3]

\begin{tabular}{cc}
\hline Practice & Description \\
\hline $\begin{array}{c}\text { Understanding } \\
\text { technological } \\
\text { principles }\end{array}$ & $\begin{array}{c}\text { Students are able to make use of their } \\
\text { knowledge about technology. }\end{array}$ \\
Developing \\
solutions and \\
achieving goals \\
technological knowledge, tools, and \\
skills to solve problems and achieve \\
goals presented in realistic contexts. \\
Communicating and \\
collaborating & $\begin{array}{c}\text { Students are able to use contemporary } \\
\text { technologies to communicate for a } \\
\text { variety of purposes and in a variety of } \\
\text { ways, working individually or in } \\
\text { teams, with peers and experts. }\end{array}$ \\
\hline
\end{tabular}

Referring to concept of technology and engineering literacy mentioned above, it can be concluded that primary and general secondary school student's technology and engineering literacy (TEL) covers core knowledge and skills on using related available technology, developing design for solving problems as well as capability to communicate and working individually, or in teams with peers and experts or other human resources.

\section{INVESTIGATING THE TEL IMPLEMENTATION METHOD}

Based on authentic experience being involved as "education and research exchange" program with research grant from Japanese government during STEM Education study in primary and middle schools in Japan, some research observation was described as follows.

Figure 2 showed the STEM-based activity that delivered twice a week and organized by local prefecture government to support government program in improving technology and engineering literacy. Participants come from elementary and secondary school level from many district regions in the prefecture. They are talented students who like science and eager to be scientist in the future. Some university professor as a volunteer supported the activity. It emphasized on understanding science concept and technology using engineering process.

Other similar activities are delivered in Shizuoka science museum in collaborate with university professor to improve students' interest in science. It calls rika dai tsuki program that arranged once a week for six month in a year. The program has been conducted since 2010 supported by Japanese government and university grants. Participants come from elementary and secondary school level around Shizuoka city. Most of them have been participated for two until three years. Therefore, they were used to the scientific activity. Scheme of activities were changed into STEM-based since 2013 in order to encourage innovation in technology and engineering. The examples described on Figure 3.
Case Study in Fujieda Primary Education (Primary School and Middle School)

Theme in Mathematics (angle and pattern): Helicopter and Boomerang

Cross Cutting Concept: stability and change; proportion

Participants: four mixed groups of five to six students from fifth grade, sixth grade, and seven grade sitting around big tables with one box full of materials for conducting mathematics activity.

Fig 1. Case Study of STEM-Based activity to develop Technology and Engineering literacy (TEL) in Fujieda

Case Study in Rika Dai tsuki Program at Shizuoka Science museum (Primary School and Middle School)

Theme in Science: Wind Power Plant

Technology: LEGO for education

Participant six groups of three students from fifth grade, sixth grade, and seventh grade.

Engineering: they were asked to build wind power plant based on the LEGO instruction book, and measure the energy produced in one to five minutes.

Mathematics: using simple mathematics operation and graph, they analyzed the data of energy and explain the characteristic of energy over time on simple graph.

Crosscutting concept: systems model, energy

Wind is a natural resource that could move the generator to produce energy kinetics and convert it to electricity energy. LEGO for education create a prototype of wind power plant to help student

Fig 3. Case Study of STEM-Based activity to develop Technology and Engineering literacy (TEL) in Shizuoka Science Museum

In the U.S context, one of STEM education implementation at Columbia Academy conducts in the formal setting through engineering class course for secondary level. The course use project based approach that consists of three project challenges in one semester. The project challenge sets in six meeting classes. The class designs in three role-plays as seller, producer, and client. Students act as seller and producer, while the teacher act as client who judge the students' project result.

On the other U.S region, STEM education implementation method is designed as an after school activity program in the form of club, summer camp, and robotic competition. The programs have documented the increased interest, self- 
confidence or positive attitude toward STEM field [11]. The program samples are listed in the table 2.

TABLE 2. STEM Program Activity Sample

\begin{tabular}{|c|c|}
\hline PROGRAM & ACTIVITY \\
\hline $\begin{array}{l}\text { CSTEM } \\
\text { (Communication } \\
\text { STEM) }\end{array}$ & $\begin{array}{l}\text { Focused on professional development for } \\
\text { teacher who are leading the robotic team }\end{array}$ \\
\hline For Inspiration & First Robotic competition and First Tech \\
\hline and Recognition & Challenge for high school students. First \\
\hline of Science and & LEGO League for 9-14 years old, and Junior \\
\hline $\begin{array}{l}\text { Technology } \\
\text { (FIRST) }\end{array}$ & LEGO League for 6-8 youth years old. \\
\hline Operate & Summer program than conducted by Girls \\
\hline SMART & $\begin{array}{l}\text { Inc. Students spend time working on science } \\
\text { experiments, designing project and having } \\
\text { discussion about career. }\end{array}$ \\
\hline $\begin{array}{l}\text { Science Club for } \\
\text { Girls (SCPG) }\end{array}$ & $\begin{array}{l}\text { Operates out of Cambridge, MA, at school } \\
\text { site throughout the state. Girls } 8^{\text {th }}-12^{\text {th }} \text { grade } \\
\text { build leadership skills by serving as mentors } \\
\text { to younger girls (K-7) }\end{array}$ \\
\hline $\begin{array}{l}\text { 4H- afterschool } \\
\text { and summer } \\
\text { program }\end{array}$ & $\begin{array}{l}\text { STEM activity focuses to build process } \\
\text { science skills in recording data accurately, } \\
\text { using data to create graph, and using result of } \\
\text { investing to answer questions. }\end{array}$ \\
\hline
\end{tabular}

In Indonesia, STEM-based activity was introduced in regular class through an engineering practice in making balloon-powered car[7]. It aims to deliver linear motion concept on science subject to secondary level students. They were asked to create simple car from ice cream stick that moved by balloon power. Students work in-group to identify the problem, brainstorming, design, construct, test, and reconstruct the car. The impact of the activity resulted in students' positive response toward learning processes. Most of students said that they enjoy it (100\%), it make them move and think actively (90\%), and understand the concept easier $(80 \%)$. However, there are some challenges in implementing technology (T) and engineering (E) into STEM-based activity, thus it needs further research and implementation

\section{DISCUSSION}

Analyzing many method varieties of STEM implementation method in U.S, Japan, and Indonesia, we found that the activity engage students in engineering practice design which train students to have Technology and Engineering literacy. However, the implementations need support from decision maker and stakeholders, not only school level but also university level. It is coherence to the project 2061 that released by AAAS (2009).

Project 2061 promotes literacy in science, mathematics, and technology in order to help people live interesting, responsible, and productive lives [4]. In a culture increasingly pervaded by science, mathematics, and technology, science literacy requires understandings and habits of mind that enable citizens to grasp what those enterprises are up to, to make some sense of how the natural and designed worlds work, to think critically and independently, to recognize and weigh alternative explanations of events and design trade-offs, and to deal sensibly with problems that involve evidence, numbers, patterns, logical arguments, and uncertainties. In other words, if it is expected that the students will be literate in Technology and Engineering in science learning then they should have real experience through science learning that addresses the particular needs and interests of individual students.

If we want students to learn science, technology, engineering and mathematics well, we must radically reduce the sheer amount of material now being covered. Goals should be stated so as to reveal the intended character and sophistication of learning to be sought. Although goals for knowing, designing, and doing can be described separately, they should be learned together in many different contexts so that they can be used together in life outside of school.

The common core of learning in science, technology, engineering and Mathematics (STEM) should center on STEM Literacy, not on an understanding of each of the separate disciplines. Moreover, the core studies should include connections among science, technology, engineering and mathematics, and between those areas and the arts and humanities and the vocational subjects, by using engineering practice design. In STEM Education terminology, it is recognized as cross cutting concepts [5]. The coverage of cross cutting concepts are listed as follows: pattern (i), cause and effect (ii), scale (iii), proportion (iv), quantity (v), systems and system models (vi), energy and matters (vii), stability and change (vii).

The core idea of engineering design includes three component ideas (iterative cycle of engineering design)[6]: defining and delimiting engineering problems (i); designing solutions to engineering problems (ii); and optimizing the design solution (iii). It is important to have in mind that engineering design should be related to student diversity. This core idea, engineering offers opportunities for innovation and creativity at primary and secondary school levels.

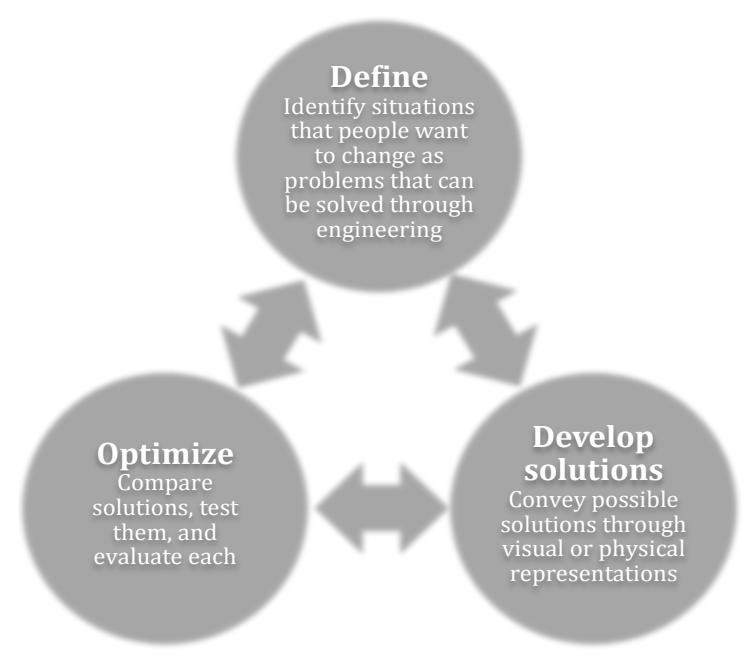

Fig 3. Iterative cycle of engineering design diagram

source: NGSS, 2013

In project 2061, benchmarks can be used to facilitate learning progress from other countries or valuable sources. Benchmark 
is a report from a cross-section of practicing educators. Japan learns and develops their STEM education from NGSS and K12 Framework on Science subjects from USA.

\section{SUMMARY}

Efforts to make the Technology and Engineering Literacy possible in the empowering of out of school (informal education) activities in some school levels and at university level who work collaboratively in School-University Linkage with some supports from other institutions, among others. It is need to be realized seriously by decision makers and stakeholders in both country through Joint Seminars, joint researches and mutual aspects, and actions from ScienceTechnology-Mathematics teachers and the ScienceTechnology-Mathematics educators.

\section{ACKNOWLEDGMENTS}

This paper was prepared as one of the results of Educational and Research Exchange at Shizuoka University Japan, funded by Research Grand from the Japanese Government in October-December 2014 and January-February 2015, promoted by the Dean of Faculty of Education, Shizuoka University and Yoshisuke KUMANO, Ph.D.

\section{REFERENCES}

[1] Pearson, G., \& Young, T. (Eds.) (2002). Technically speaking: Why all American needs to know more about technology. Washington, D.C.: National Academies Press.
[2] Honey, M., Pearson, G., \& Schweingruber (Eds.) (2014). STEM integration in K-12 education. Washington, D.C.: The National Academies Press.

[3] National Assessment and Educational Progress (2012). Technology and Engineering Literacy (TEL) Assessment. Retrieved at July 5, (2015) from http://nces.ed.gov/ nationsreportcard

[4] American Association for the Advancement of Science. (2009). Benchmarks of Science Literacy. Science For All American (SFAA). online.

[5] Next Generation Science Standard (NGSS), (2013), Appendix G: Crosscutting Concept, Retrieved at March 17, 2013 from http://ngss.org

[6] Next Generation Science Standard (NGSS), (2013), Appendix F: Engineering Practice, Retrieved at March 17, 2013 from http://ngss.org

[7] Suwarma Irma Rahma, et al (2015). "Balloon Powered Car" sebagai Media Pembelajaran IPA Berbasis STEM (Science, Technology, Engineering, And Mathematics), Proceeding Seminar Nasional Inovas Pembelajaran Sains 2015, Institut Teknologi Bandung[Bandung Institute of Technology]

[8] Kumano, Y. et al. (2013) "Analysis and discussion on STEM education movement in Science Education in the US and possible Implication to the Japanese and Indonesian contexts", Paper presented in collaborative Japan-Indonesia Seminar held in Bandung.

[9] National Research Council, (2012). A Framework for K-12 Science Education. The National Academies Press. 1-385.

[10] Rustaman, N.Y. (2014). The Next Generation Science Standards (NGSS) and Science-Technology-Engineering-Mathematics (STEM) education movement: The challenge (faced) in preparing reflective Science teacher. in the $6^{\text {th }}$ International Conference of Teacher Education (UPI-UPSI) entitle "The Standardization of Teacher Education: Asian Qualification Framework" held in Bandung, 25-26 June 2014.

[11] Afterschool Alliance, (2011). Afterschool: A Vital Partner in STEM Education. Retrieved at March 2013 from http://www.afterschoolalliance.org/Afterschool_as_STEMpartner.pdf.

[12] Afterschool Alliance (2009). America After 3pm, Retrieved at March 2013 from http://www.afterschoolalliance.org/AA3PM.cfm. 